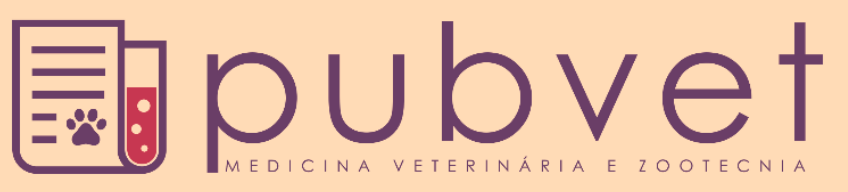

https://doi.org/10.31533/pubvet.v15n12a980.1-6

\title{
Leishmaniose visceral em canino: Relato de caso
}

\author{
Aishá Ingrid de Sousa Brito ${ }^{1^{*}}$, Rebeca Iaínia Pereira ${ }^{1} \theta$, Tahise Magalhães de Oliveira ${ }^{2} \bullet$, \\ Milton Rezende Teixeira Neto ${ }^{2} \bullet$, Luiz Di Paolo Maggitti Junior ${ }^{3} \bullet$
}

${ }^{I}$ Discentes do curso de Medicina Veterinária do Centro universitário UNIFTC, Vitória da Conquista, Bahia, Brasil.

${ }^{2}$ Docentes do curso de Medicina Veterinária do Centro universitário UNIFTC, Vitória da Conquista, Bahia, Brasil.

${ }^{3}$ Médico Veterinário pela Universidade Federal da Bahia - UFBA, Salvador, Bahia, Brasil.

*Autor para correspondência, E-mail: aisha.ingrid@hotmail.com

\begin{abstract}
Resumo. A Leishmaniose Visceral ou Calazar é uma zoonose que tem se disseminado rapidamente na Bahia por conta do processo de urbanização. O relato de caso tem como objetivo definir a importância do diagnóstico e tratamento da doença em cães, mostrando desde a identificação da enfermidade pelo médico veterinário, exames laboratoriais, citológico e de imagem. O estudo foi realizado em um hospital veterinário 24 horas, localizado na cidade de Vitória da Conquista, no interior da Bahia. O paciente foi um canino, macho e fértil, da raça American Staffordshire Terrier com nove meses e 14 dias de idade, pesando $22 \mathrm{~kg}$, com vacinação de raiva e múltipla viral e vermifugação em dia. Após a confirmação da suspeita clínica através da Reação em Cadeia da Polimerase -PCR para Leishmania sp, da punção aspirativa por agulha fina e exame hematológico e de imagem, o animal teve todo suporte para controle dos sintomas e foi iniciado o protocolo de tratamento da leishmaniose com a associação de domperidona, milteforan e alopurinol, além do início do protocolo vacinal com a vacina leishtec e a utilização de coleiras repelentes.
\end{abstract}

Palavras-chave: Cães, calazar, epidemiologia

\section{Visceral leishmaniasis in a canine: Case report}

\begin{abstract}
The Visceral Leishmaniasis or Kala-azar is a zoonosis that has spread quickly in Bahia because of the urbanization process. The case report has the objective of defining the importance of diagnosis and treatment of the disease in dogs, showing from the illness identification by the veterinary doctor, laboratory tests, cytological and imaging. The study was conducted in a 24 hours veterinary hospital, located in the city of Vitória da Conquista, in Bahia's countryside. The patient was a canine, male and fertile, American Staffordshire Terrier breed of nine months and fourteen days old, weighing $22 \mathrm{~kg}$, with rabies, viral multiple and vermifugation vaccines up to date. After the confirmation of clinical suspicion through the Polymerase Chain Reaction - PCR for leishmania sp, by fine needle aspiration puncture and hematological and imaging exam, the animal had fully support for symptom control and the leishmaniasis treatment protocol was initiated with the association of domperidone, milteforan, allopurinol, in addition to the beginning of the vaccination protocol with the leishtec vaccine and the use of repellent collars.
\end{abstract}

Keywords: Kala-aza, dogs, epidemiology

\section{Introdução}

A leishmaniose visceral canina (LVC) ou calazar, é causada pelo protozoário Leishmania sp., um protozoário intracelular obrigatório, que apresenta as formas parasitárias de promastigota, que se desenvolvem e multiplicam no interior do mosquito vetor, promastigotas metacíclicas e a forma 
amastigota. A LVC é transmitida principalmente por flebotomíneos, sendo considerada uma zoonose que pode causar lesões cutâneas, mucocutâneas e viscerais nos mamíferos (Koutinas \& Koutinas, 2014).

O cão é considerado o principal reservatório urbano da Leishmania e a transmissão é facilitada quando há locais de predileção do vetor (matas, locais úmidos e sombreados), mas devido a sua adaptação pode estar presente em ambientes incomuns. De acordo com a epidemiologia da enfermidade, o período de maior transmissão ocorre após a estação chuvosa, motivado pelo aumento considerável dos mosquitos (Chagas, 2017; Brasil, 2014).

O diagnóstico da leishmaniose visceral possui extrema importância no controle e eliminação do parasito. Um método comum menos invasivo e prático é a punção aspirativa por agulha fina. E quando o animal apresenta lesões cutâneas ulceradas, essas podem ser escarificadas ou poderá ser feito imprint do local. Pode-se utilizar também a técnica de Reação em Cadeia da Polimerase (PCR), onde se detecta o DNA do protozoário, a partir do sangue total, medula óssea, linfonodos, pele e raspado conjuntival (Alves et al., 2015; Braz et al., 2015; $\underline{\text { Ikeda et al., 2003; }}$ Paz et al., 2010).

As medidas preventivas são necessárias para minimizar a quantidade de animais acometidos e a vigilância epidemiológica tem o papel de mapear a casuística e propor estratégias de controle referentes ao vetor, o cão e o homem, levando em consideração o agravo das áreas endêmicas (Brasil, 2014).

Esse trabalho tem como objetivo demonstrar a importância do diagnóstico e tratamento da leishmaniose em animais de companhia descrevendo conduta diagnóstica, terapêutica utilizada e evolução dos exames laboratoriais.

\section{Relato de caso}

Foi atendido em um hospital veterinário 24 horas na região de Vitória da Conquista, Bahia, um paciente canino, macho e fértil, da raça American Staffordshire Terrier com nove meses e 14 dias de idade, pesando $22 \mathrm{~kg}$, com vacinação de raiva e múltipla viral e vermifugação atualizadas. A tutora trouxe como queixa principal ressecamento no nariz, boca com mau cheiro, lesões exsudativas, lesões com sangramento ao redor do olho além de alopecia nessa região.

No exame clínico foram observadas mucosas hiperêmicas, região periorbital com crostas e secreção viscosa, lesão de pele e alopecia (Figura 1); porém, reflexo pupilar normal. O paciente apresentava lesões ao redor da boca com área de alopecia e aumento de volume, sendo que a temperatura corpórea se encontrava com $39,2^{\circ} \mathrm{C}$ e o tempo de preenchimento capilar foi de dois segundos. O linfonodo submandibular estava pouco reativo, existindo a presença de nódulos bilaterais maiores que $2 \mathrm{~cm}$ próximos aos linfonodos submandibulares, os linfonodos poplíteos estavam aumentados bilateralmente. $\mathrm{O}$ animal se encontrava apático, permanecendo em decúbito, suspeitando-se então de leishmaniose visceral canina.

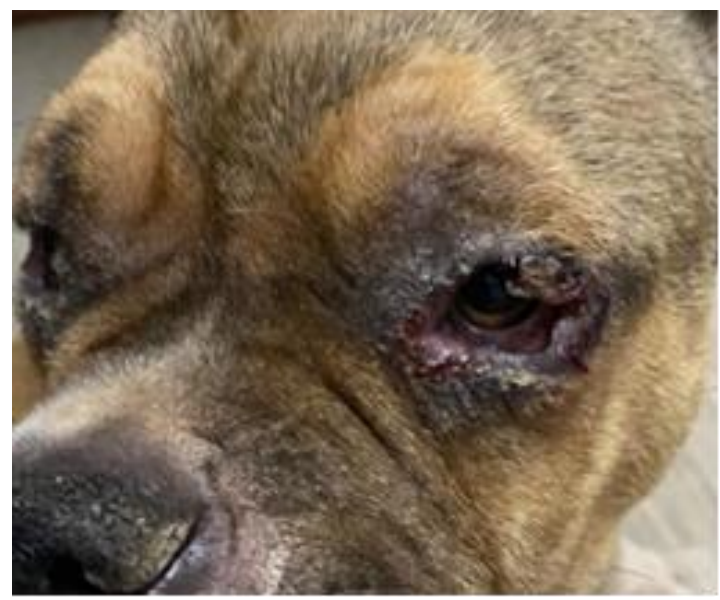

Figura 1. Canino com suspeita de leishmaniose visceral canina apresentando lesão com sangramento ao redor dos olhos e ressecamento no nariz.

Foi solicitado o perfil completo canino, sendo realizados os exames hematológico, creatinina, proteínas totais e frações, fosfatase alcalina e a dosagem de TGP (ALT). Também foi solicitado a punção 
de linfonodo por punção aspirativa por agulha fina, exames de imagem como a radiografia e a ultrassonografia e a PCR qualitativo para Leishmania sp.

O exame hematológico não apresentou alterações consideráveis para diagnóstico da doença (Tabela 1), revelando uma neutrofilia, onde o nível alto de bastonetes poderia ser indicativo de infecção bacteriana e os exames bioquímicos apresentaram a alanina aminotransferase - ALT com valores altos, podendo ser indicativa de inflamação, infecção ou intoxicação (Tabela 2).

Tabela 1. Perfil hematológico de cão, da raça American Staffordshire Terrier.

\begin{tabular}{lcc}
\hline Parâmetros & Resultados & Referências \\
\hline Eritrograma & & 6,0 a $7,0 \mathrm{milhões} / \mathrm{mm} 3$ \\
Hemácias & $6,63 \mathrm{milh} / \mathrm{mm} 3$ & $14 \mathrm{a} 17 \mathrm{~g} / \mathrm{dL}$ \\
Hemoglobina & $15,0 \mathrm{~g} / \mathrm{dL}$ & $40 \mathrm{a} 47 \%$ \\
Hematócrito & $45 \%$ & $65 \mathrm{a} 78 \mathrm{fl}$ \\
V.C.M & $68 \mathrm{fl}$ & $21-25 \mathrm{pg}$ \\
H.C.M & $23 \mathrm{pg}$ & $30 \mathrm{a} 35 \%$ \\
C.H.C.M & $33 \%$ & $5,0 \mathrm{a} 7,0 \mathrm{~g} / \mathrm{dL}$ \\
Proteínas totais & $6,4 \mathrm{~g} / \mathrm{dL}$ & $175.000-500.000 \mathrm{~mm} 3$ \\
Plaquetas & $176.000 \mathrm{~mm} 3$ & \\
\hline Leucograma & & $8.000-16.000 / \mathrm{mm} 3$ \\
Leucócitos & $14.600 / \mathrm{mm} 3$ & 0 a 200 \\
Bastonetes & $6 / 876$ & $4.500 \mathrm{a} 11.200$ \\
Segmentados & $68 / 9.928$ & $100 \mathrm{a} 1.000$ \\
Eosinófilos & $1 / 146$ & $1.600 \mathrm{a} 6.400$ \\
Linfócitos Típicos & $25 / 3.650$ &
\end{tabular}

A Leishmaniose se apresenta como uma doença crônica, onde a resposta leucocitária modela-se conforme a evolução da doença. Sendo assim, o exame pode demonstrar uma leucocitose por neutrofilia em associação com desvio à esquerda, visto que, uma infecção bacteriana secundária pode ocorrer simultaneamente (Alves et al., 2015; Braz et al., 2015; Maia et al., 2013). No presente caso não foi observada leucocitose ou leucopenia, o que pode estar justificado pela evolução da doença, sinais clínicos presentes, resposta imune e infecções secundárias presentes (Abbiati et al., 2019; Monteiro et al., 2005; Silva \& Winck, 2018).

Tabela 2. Perfil bioquímico de cão, da raça American Staffordshire Terrier.

\begin{tabular}{lcc}
\hline Bioquímico & Resultado & Referência \\
\hline ALT (TGP) & $104,8 \mathrm{U} / \mathrm{L}$ & 10,0 a $88,0 \mathrm{U} / \mathrm{L}$ \\
Creatinina & $6,63 \mathrm{milh} / \mathrm{mm} 3$ & 6,0 a 7,0 milhões $/ \mathrm{mm} 3$ \\
Fosfatase Alcalina & $15,0 \mathrm{~g} / \mathrm{dL}$ & 14 a $17 \mathrm{~g} / \mathrm{dL}$ \\
Hematócrito & $45 \%$ & 40 a $47 \%$ \\
V.C.M & $68 \mathrm{fl}$ & 65 a $78 \mathrm{fl}$ \\
H.C.M & $23 \mathrm{pg}$ & $21-25 \mathrm{pg}$ \\
C.H.C.M & $33 \%$ & 30 a $35 \%$ \\
Proteínas totais & $6,4 \mathrm{~g} / \mathrm{dL}$ & 5,0 a $7,0 \mathrm{~g} / \mathrm{dL}$ \\
\hline
\end{tabular}

No exame citopatológico foram observadas formas amastigotas de Leishmania sp. (Figura 2). O método molecular PCR, teve resultado conclusivo para Leishmania sp. confirmando a presença do protozoário na amostra pesquisada. A técnica possui especificidade e sensibilidade para superiores a 95\% na amostra adequada (há detecção até mesmo em amostras com baixa carga do agente).

No diagnóstico ultrassonográfico foi evidenciado aumento de linfonodos esplênicos e inguinais. O paciente apresentou esplenomegalia, hepatomegalia, apresentando linfoadenomegalia, sendo sugestivo de processo inflamatório/infeccioso. Já no laudo radiográfico revelou um aumento de volume das partes moles, em margem ventral ao terço caudal da mandíbula no estudo laterolateral, onde a imagem pode estar relacionada com aumento do linfonodo e/ ou edema.

O animal foi diagnosticado com o estágio 2 (doença moderada) da Leishmaniose Visceral Canina onde, além dos sinais leves, os animais apresentam lesões cutâneas difusas ou simétricas, como 
dermatite esfoliativa, onicogrifose, ulcerações (mucosa nasal, coxins plantares, proeminências ósseas, junções mucocutâneas), anorexia, emagrecimento, febre, epistaxe (Abbiati et al., 2019; Solano-Gallego et al., 2011).

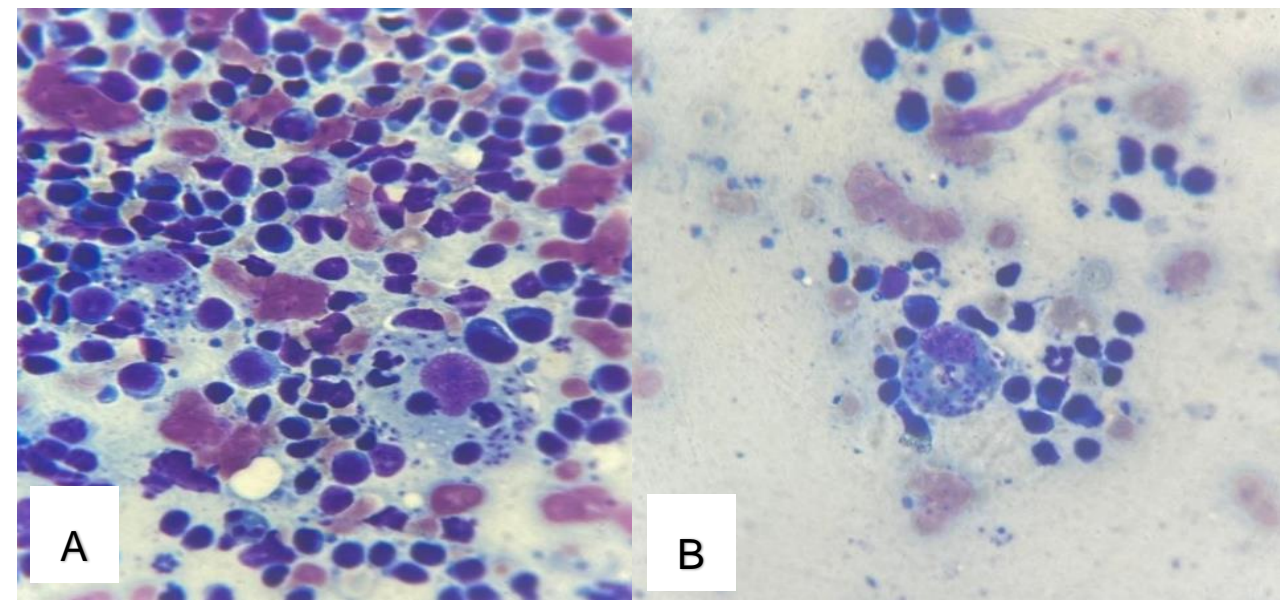

Figura 2. (A) Citologia de amostra obtida por punção aspirativa por agulha fina de linfonodo de um cão com leishmaniose, apresentando vários linfócitos e também macrófagos contendo vários organismos Leishmania sp. (Microscopia óptica x 100 com coloração panótipo) (B) As setas indicam a forma amastigota próxima a um macrófago, os organismos de Leishmania sp. são pequenos, redondos e ovais, com citoplasma claro e levemente azul.

O tratamento foi realizado com Prednisolona como anti-inflamatório de escolha para tratamento das lesões e inflamações e Dipirona como analgésico. Foi realizada a associação da Domepridona com a Mitelfosina a 2\% (Milteforan) e o Alopurinol (Zyloric).

\section{Discussão}

Atualmente, de acordo com a legislação brasileira, o tratamento de cães só é permitido com medicamentos registrados no Ministério da Agricultura, Pecuária e Abastecimento (MAPA) e que não sejam utilizados no tratamento de seres humanos acometidos pela doença. $O$ único fármaco que atende as condições vigentes e que está sendo comercializado no Brasil é o Milteforan, cujo princípio ativo é a Miltefosina.

O Milteforan é uma droga que permite o controle da doença, impedindo dessa forma a sua difusão. A dose utilizada é de $2 \mathrm{mg} / \mathrm{kg}$ por dia, o equivalente a $1 \mathrm{~mL} / 10 \mathrm{~kg}(20 \mathrm{mg} / \mathrm{mL})$, administrado junto com as refeições, durante o período de 28 dias. $\mathrm{O}$ vômito, efeito adverso comum, pode ser evitado com o emprego do antiemético (Mitelforan).

Já o alopurinol é uma droga leishmaniostática e apresenta uma eficácia maior quando é empregado em associação, sendo de uso contínuo para o tratamento da leishmaniose. A domperidona é inserida no protocolo com o objetivo de imunomodulação, reduzindo a sintomatologia presente nos cães com a doença. O animal utilizará coleiras repelentes impregnadas com Deltametrina a $4 \%$ por toda sua vida, para evitar a picada do flebotomíneo e iniciou o protocolo vacinal com a vacina leishtec com a aplicação de duas doses da vacina em três momentos, sendo que a vacinação de cães contra leishmaniose visceral canina é um importante passo na direção ao controle da doença nos cães e, consequentemente, em humanos (Moreira, 2013).

O Ministério da Saúde realizou estudo em alguns municípios sobre a efetividade do uso em grande escala da coleira com Deltametrina $4 \%$. O resultado demonstrou que o encoleiramento em massa produz efeito protetor efetivo não só dos que usam as coleiras, mas também nos não encoleirados (Coura-Vital et al., 2018; Orlandi, 2011).

No último retorno ao hospital veterinário, o animal recuperou seu score corporal, não apresentando nenhum sinal clínico da doença, as lesões ao redor dos olhos foram cicatrizadas e nos exames hematológicos e bioquímicos não houve alterações significativas, mostrando que a doença tem sido controlada e o animal vem respondendo ao tratamento (Figura 3). 
Atualmente, a eliminação de cães soropositivos é realizada apenas no Brasil, mas a ação parece não ser efetiva e devido às várias formas de manifestações clínicas da doença, surgem dificuldades para o diagnóstico, sendo que cães sintomáticos e assintomáticos são infectantes para o vetor. Na Europa, por exemplo, é realizado tratamento contra a doença com medicamentos de uso veterinário, produzidos por laboratórios consagrados, como Merial e Virbac (Moreira, 2013; Schimming \& Silva, 2012).

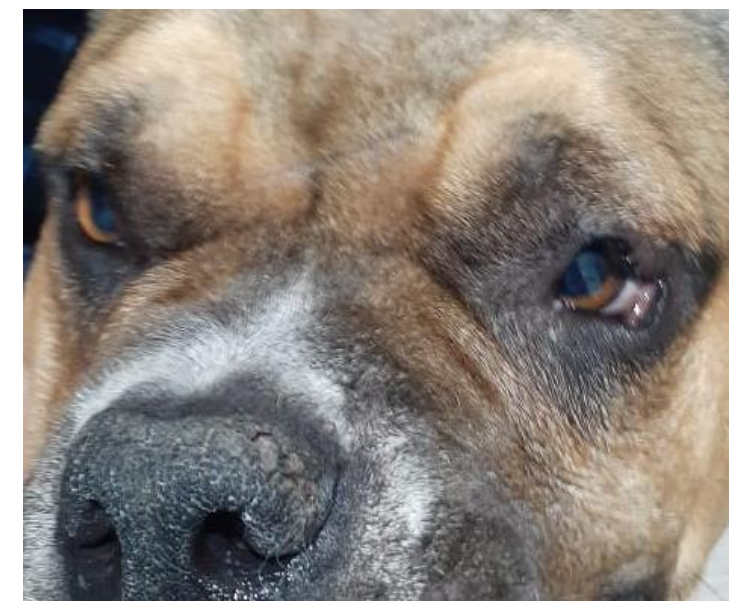

Figura 3. Canino com leishmaniose visceral canina com lesões nos olhos cicatrizadas.

\section{Conclusão}

A leishmaniose visceral é uma zoonose importante e de notificação obrigatória por oferecer risco a população humana e canina local. O cão é o principal reservatório do protozoário, caracterizando-se como uma fonte de infecção para outros cães e para o homem, sendo assim, a sua susceptibilidade é ampliada quando estão inseridos em locais endêmicos ou possuem o estilo de vida livre. A patologia deve receber dada atenção para que através da sensibilização dos proprietários possa ser realizada de forma correta a fundamental medida de prevenção, tratamento e controle. Neste relato, o animal teve todo tratamento de suporte necessário e apresentou melhoras consideráveis no quadro clínico, sendo possível estabelecer uma boa qualidade de vida para o mesmo. Logo, o Médico Veterinário deve ter a consciência da sua responsabilidade perante o animal e a sociedade, visando a saúde pública de maneira integral.

\section{Referências bibliográficas}

Abbiati, T. C., Freitas, D. M., Alves, L. C., Freitas, B. G., Rezende, R. S., Barbosa, S. G., Jorge, A. L. T. A., Santos, S. M., \& Lopes, M. C. (2019). Leishmaniose visceral canina: Relato de caso. PUBVET, 13, 1-8. https://doi.org/10.31533/pubvet.v13n4a307.1-8.

Alves, M. M. M., Mendonça, I. L., Batista, J. F., Rocha, F. S. B., \& Carvalho, E. M. (2015). Perfil hematológico de cães naturalmente infectados por Leishmania chagasi. PUBVET, 9(4), 158-194.

Brasil (2014). Ministério da Saúde. Manual de vigilância e controle da leishmaniose visceral. Editora do Ministério da Saúde, 1.ed., Brasília, Brasil.

Braz, P. H., Sartoretto, M. C., Souza, A. S., \& Melo, F. M. G. (2015). Perfil hematológico de cães naturalmente infectados por Leishmania spp. Acta Veterinaria Brasilica, 9(1), 87-90.

Chagas, R. L. D. A. (2017). Leishmaniose visceral canina: perfil epidemiológico do Distrito Federal, 2013 a 2017.

Coura-Vital, W., Leal, G. G. A., Marques, L. A., Pinheiro, A. D. C., Carneiro, M., \& Reis, A. B. (2018). Efetividade de coleiras impregnadas de deltametrina na incidência de infecção canina por Leishmania infantum: um estudo de intervenção em larga escala em uma área endêmica no Brasil. Plos One, 13(12). https://doi.org/10.1371/journal.pone.0208613.

Ikeda, F. A., Ciarlini, P. C., Feitosa, M. M., Gonçalves, M. E., Luvizotto, M. C. R., \& Lima, V. M. F. (2003). Perfil hematológico de cães naturalmente infectados por Leishmania chagasi no município de Araçatuba-SP: um estudo retrospectivo de 191 casos. Clínica Veterinária, 47, 42-48. 
Koutinas, A. F., \& Koutinas, C. K. (2014). Pathologic mechanisms underlying the clinical findings in canine leishmaniosis due to Leishmania infantum/chagasi. Veterinary Pathology, 51(2), 527-538. https://doi.org/10.1177/0300985814521248.

Maia, C., Nunes, M., Marques, M., Henriques, S., Rolão, N., \& Campino, L. (2013). In vitro drug susceptibility of Leishmania infantum isolated from humans and dogs. Experimental Parasitology, 135(1), 36-41. https://doi.org/10.1016/j.exppara.2013.05.015.

Monteiro, E. M., Silva, J. C. F., Costa, R. T., Costa, D. C., Barata, R. A., Paula, E. V., Machado-Coelho, G. L. L., Rocha, M. F., Fortes-Dias, C. L., \& Dias, E. S. (2005). Leishmaniose visceral: estudo de flebotomíneos e infecção canina em Montes Claros, Minas Gerais. Revista da Sociedade Brasileira de Medicina Tropical, 38(2), 147-152.

Moreira, M. L. (2013). Duração da imunidade vacinal na Leishmaniose visceral canina: Perfil fenotípico e funcional da atividade fagocítica anti-Leishmania chagasi. Osvaldo Cruz Fundação.

Orlandi, V. T. (2011). Proposta de inclusão do encoleiramento em massa no programa de controle da leishmaniose visceral. Clínica Veterinária, 16(92), 1-16.

Paz, G. F., Ribeiro, M. F. B., Magalhães, D. F., Sathler, K. P. B., Morais, M. H. F., Fiúza, V. O. P., Brandão, S. T., Werneck, G. L., Fortes-Dias, C. L., \& Dias, E. S. (2010). Association between the prevalence of infestation by Rhipicephalus sanguineus and Ctenocephalides felis and the presence of anti-Leishmania antibodies: A case-control study in dogs from a Brazilian endemic area. Preventive Veterinary Medicine, 97(2), 131-133.

Schimming, B. C., \& Silva, J. R. C. P. (2012). Leishmaniose visceral canina - Revisão de literatura. Revista Científica Eletrônica de Medicina Veterinária, 10(18), 1-5.

Silva, C. M. H. S., \& Winck, C. A. (2018). Leishmaniose visceral canina: revisão de literatura. Revista da Universidade Vale do Rio Verde, 16(1), 1-12.

Solano-Gallego, L., Miró, G., Koutinas, A., Cardoso, L., Pennisi, M. G., Ferrer, L., Bourdeau, P., Oliva, G., \& Baneth, G. (2011). LeishVet guidelines for the practical management of canine leishmaniosis. Parasites \& Vectors, 4(1), 1-16. https://doi.org/10.1186/1756-3305-4-86.

Histórico do artigo:

Recebido: 11 de setembro de 2021

Aprovado: 12 de outubro de 2021

Disponível online: 9 de novembro de 2021
Licenciamento: Este artigo é publicado na modalidade Acesso Aberto sob a licença Creative Commons Atribuição 4.0 (CC-BY 4.0), a qual permite uso irrestrito, distribuição, reprodução em qualquer meio, desde que o autor e a fonte sejam devidamente creditados. 